ARTICLE

DOI: $10.1038 / \mathrm{s} 41467-017-01006-4$

\title{
Electro-osmotic capture and ionic discrimination of peptide and protein biomarkers with FraC nanopores
}

\author{
Gang Huang ${ }^{1}$, Kherim Willems (10 ${ }^{2,3}$, Misha Soskine${ }^{1}$, Carsten Wloka $^{1}$ \& Giovanni Maglia ${ }^{1}$
}

Biological nanopores are nanoscale sensors employed for high-throughput, low-cost, and long read-length DNA sequencing applications. The analysis and sequencing of proteins, however, is complicated by their folded structure and non-uniform charge. Here we show that an electro-osmotic flow through Fragaceatoxin C (FraC) nanopores can be engineered to allow the entry of polypeptides at a fixed potential regardless of the charge composition of the polypeptide. We further use the nanopore currents to discriminate peptide and protein biomarkers from $25 \mathrm{kDa}$ down to $1.2 \mathrm{kDa}$ including polypeptides differing by one amino acid. On the road to nanopore proteomics, our findings represent a rationale for amino-acid analysis of folded and unfolded polypeptides with nanopores.

\footnotetext{
${ }^{1}$ Groningen Biomolecular Sciences \& Biotechnology Institute, University of Groningen, 9747 AG Groningen, The Netherlands. ${ }^{2}$ KU Leuven Department of Chemistry, Celestijnenlaan 200G, 3001 Leuven, Belgium. ${ }^{3}$ Imec, Kapeldreef 75, 3001 Leuven, Belgium. Correspondence and requests for materials should be addressed to C.W. (email: c.wloka@rug.nl) or to G.M. (email: g.maglia@rug.nl)
} 
$\mathrm{n}$ nanopore biopolymer analysis, molecules are recognized by the characteristic modulation of the ionic current during their residence inside the nanopore under an external potential. Nanopore sensors are advantageous because they recognize single molecules and the ionic signal can easily be interfaced with lowcost and portable electronic devices. Most notably nanopores can be used for nucleic acid analysis ${ }^{1-7}$ and sequencing ${ }^{8-13}$ where individual DNA strands are unfolded and stretched by the electric field as they are fed through the nanopore. The analysis of proteins and polypeptides, however, is complicated by the fact that they do not possess a uniform charge distribution. Depending on its direction, the electrical field can either facilitate or retard the transport of charged residues, or have almost no net contribution to the transport of neutral amino acids. Therefore, the translocation and stretching of a polypeptide through a nanopore must be induced by other means, for example, by using enzymes ${ }^{14}$.

Previous work with biological nanopores mainly focussed on the electrophoretic-driven translocation of model peptides ${ }^{15-19}$.
More recently, it has been acknowledged that the electro-osmotic flow (EOF), induced by the fixed charges in the inner wall of the nanopore, has considerable influence on the transport mechanism of molecules across nanopores ${ }^{20-27}$. In particular, it was shown that at $\mathrm{pH} 2.8$ positively charged peptides can be trapped inside a nanopore by the balancing effect of the electrophoretic driving force and the opposing EOF through the nanopore ${ }^{27}$. This suggests that the intensity of the EOF can be as strong as the electrophoretic force and, in turn, the EOF might be used to translocate and stretch polypeptides for protein sequencing applications. However, changing the $\mathrm{pH}$ of the solution also influences the charge of the nanopore inner surface, and hence the EOF. When using biological nanopores this is an issue, since altering the $\mathrm{pH}$ to uniformly charge a polypeptide would also adversely affect the direction of the EOF. For example, at $\mathrm{pH} 2.8$, the inner surface of a biological nanopore consisting of natural amino acids would be positively charged, resulting in an EOF from cis to trans under positive applied voltages at the trans side. a

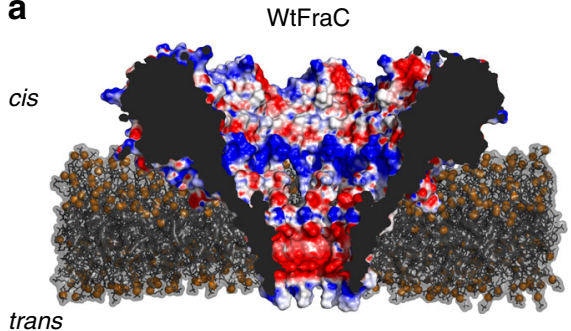

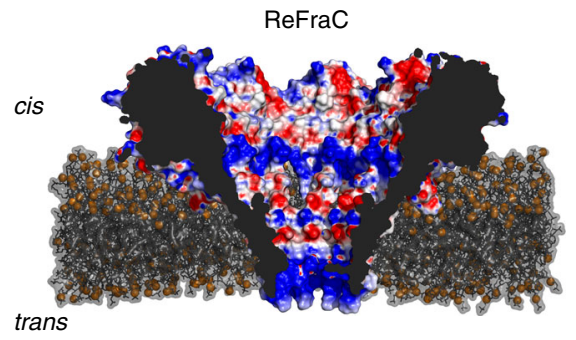

b

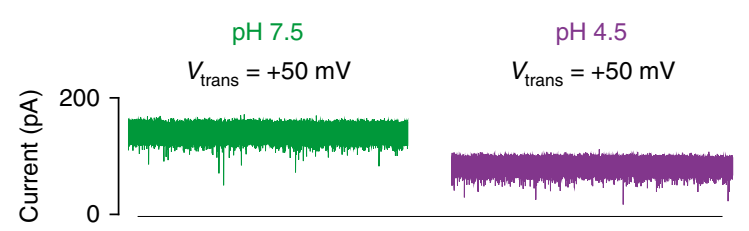

$2 \mathrm{~s}$

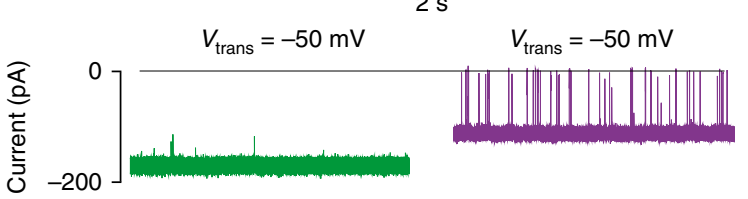

C

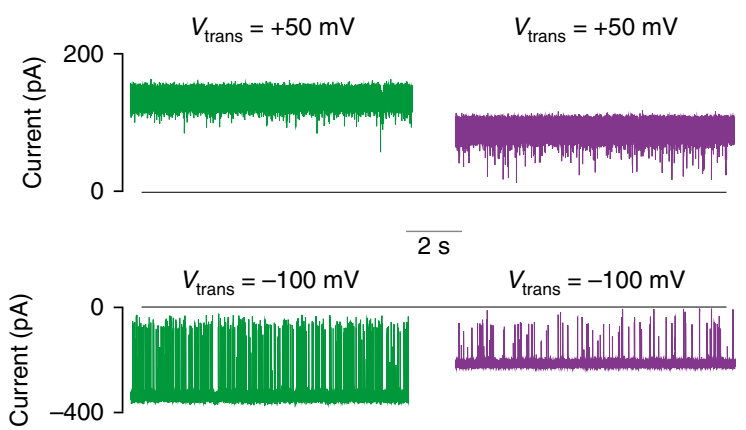

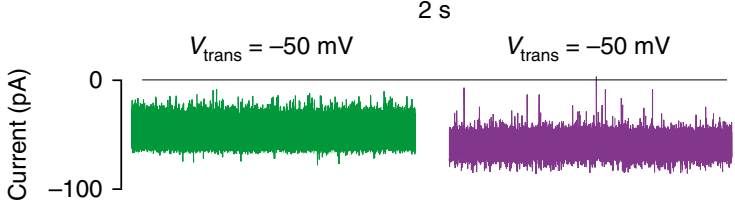

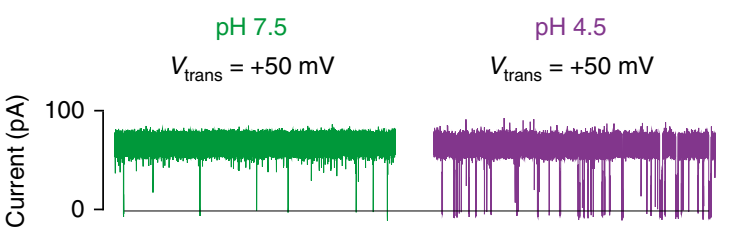

$V_{\text {trans }}=+200 \mathrm{mV} \quad V_{\text {trans }}=+200 \mathrm{mV}$

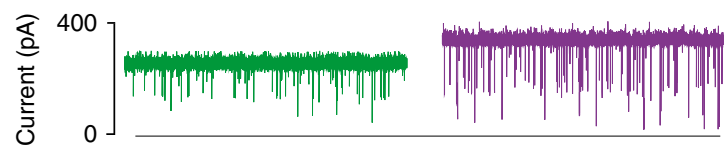

$2 \mathrm{~s}$

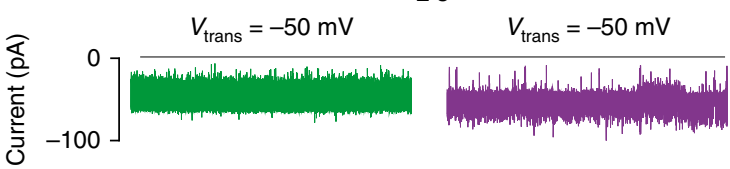

Fig. 1 Capture of endothelin 1 and chymotrypsin with two FraC variants at two different pH conditions. a Cross sections of wild-type FraC (WtFraC, PDB: 4TSY) and D10R-K159E-FraC (ReFraC). b, c Representative traces induced by $1 \mu \mathrm{M}$ endothelin 1 (b) and $200 \mathrm{nM}$ chymotrypsin (c) to WtFraC (left) and ReFraC (right). Chymotrypsin (PDB: 5CHA) and human endothelin 1 (PDB: 1EDN) are shown as surface representations. Endothelin 1 and chymotrypsin enter WtFraC under negative applied potentials, while they enter ReFraC under positive applied potentials. Chymotrypsin blockades to WtFraC were also observed under $-50 \mathrm{mV}$ at pH 7.5 and 4.5 ; however, the applied potential was increased to $-100 \mathrm{mV}$ to obtain a sufficient number of blockades. At pH 7.5, blockades to ReFraC by chymotrypsin under positive applied bias required higher potential than to WtFraC under negative applied bias. The buffer at $\mathrm{pH}$ 7.5 included $1 \mathrm{M} \mathrm{KCl}, 15 \mathrm{mM}$ Tris base, and the buffer at pH 4.5 contained $1 \mathrm{M} \mathrm{KCl}, 0.1 \mathrm{M}$ citric acid, $180 \mathrm{mM}$ Tris base. Endothelin 1 and chymotrypsin were added into cis compartment. All traces were recorded using $50 \mathrm{kHz}$ sampling rate and a $10 \mathrm{kHz}$ low-pass Bessel filter. The coloring represents the electrostatic potential of the molecular surface as calculated by $\mathrm{APBS}^{75}(\mathrm{pH} 7.5$ in $1 \mathrm{M} \mathrm{KCl}$ ) with red and blue corresponding to negative and positive potentials (range from -4 to $+4 k_{\mathrm{B}} T / e_{c}$ ), respectively. Structures were rendered using PyMOL 
The positive applied potential, however, opposes the translocation of the protonated polypeptides.

Folded proteins can also be characterized with nanopores. Biological nanopores such as $\mathrm{OmpG}^{28,29}, \alpha \mathrm{HL}^{14,30}$, phi29 DNApackaging motor $^{31}$, and $\mathrm{FhuA}^{32}$ have been used to recognize proteins interacting at the entry of the nanopore. More recently, we have shown that folded proteins can be sampled using the larger ClyA nanopore, where the EOF traps proteins with a certain size inside the $\sim 6 \times 10 \mathrm{~nm}$ nanochamber of the nanopores ${ }^{23}$, 33-36. Inside the nanopore, proteins remain folded and the ionic current can distinguish between different protein ${ }^{23}$, isomeric DNA:protein binding configurations ${ }^{34}$, and ligand-induced conformational changes ${ }^{36}$. Work with solid-state nanopores with a large diameter revealed that globular proteins might translocate too quickly across nanopores to be properly sampled ${ }^{37}$. However, if the diffusion of the protein is controlled by modulation of $\mathrm{pH}^{38}$, immobilization within the nanopore's walls ${ }^{39}, 40$ or by the interaction between a protein and the nanopore ${ }^{41-43}$, ionic current blockades can be used to identify proteins.

The shape, size, and surface charge of the nanopore are important factors for the recognition of proteins. Proteins with different masses have been studied with different size glass and solid-state nanopores. The groups of Keyser ${ }^{44}$ and Radenovic ${ }^{45}$ used glass nanopores with diameters of $>20 \mathrm{~nm}$ for the analysis of proteins ranging from 12 to $480 \mathrm{kD}$ relying on the electrophoretic force for protein capture. Wanunu and co-workers ${ }^{46,47}$ fabricated smaller solid-state pores $(\sim 5 \mathrm{~nm}$ diameter $)$ to separate sub- $30 \mathrm{kD}$ proteins ( $28.9 \mathrm{kD}$ ProtK and $13.7 \mathrm{kD}$ RNaseA) and found that the osmotic flow dominated the transport for most of the proteins analyzed. Meller's group ${ }^{38}$ used even a smaller solid-state pore $(3 \mathrm{~nm}$ diameter) to sample ubiquitin $(8.5 \mathrm{kD})$ and achieved the separation of ubiquitin chains of different lengths including ubiquitin dimers $(\sim 17 \mathrm{kD})$ of two different conformations. Recently, we showed also the real-time ubiquitination of a model protein with ClyA nanopore ${ }^{48}$. However, the detection and separation of peptides and small proteins are still very challenging and has not been achieved to our knowledge. Moreover, the charge and EOF need to be more carefully tuned for the capture and transport of sub- $10 \mathrm{kD}$ polypeptides, complicating the establishment of general conditions for the detection of such small analytes.

Recently we characterized an $\alpha$-helical pore-forming toxin from an actinoporin protein family Fragaceatoxin $\mathrm{C}$ (FraC) for DNA analysis ${ }^{49}$. The crystal structure revealed that FraC consists of eight small subunits that describe a basket-shaped nanopore with a large opening of $\sim 6 \mathrm{~nm}$ diameter at the cis entry. The transmembrane region of $\mathrm{FraC}$ is formed by eight V-shaped $\alpha$ helices that taper down toward a narrow constriction of $\sim 1.5 \mathrm{~nm}$ at the trans entry of the pore (Fig. $1 \mathrm{a})^{50}$. Thus, the narrow constriction of FraC appears ideally suited for protein-sequencing applications, while the large vestibule described by the cis lumen of the nanopore might be ideal to characterize small folded proteins. In this work, we use FraC nanopores to recognize biomarkers in the form of oligopeptides ( $\leq 10$ amino acids), polypeptides ( $>10$ amino acids), and folded proteins ( $>50$ amino acids). We find that the precise tuning of the charges present in the constriction of the nanopore is important to allow the translocation of oppositely charged polypeptides through $\mathrm{FraC}$ nanopores. Once inside the nanopore, polypeptides could be identified by their ionic current blockades, suggesting that this technology can be suitable for the proteomic characterization of biological samples.

\section{Results}

Protein capture with FraC nanopores. To assess FraC nanopores as a sensor for peptide and protein biomarkers, we initially selected endothelin 1 , a $2.5 \mathrm{kD}$ polypeptide of 21 amino acids and $\alpha$-II-chymotrypsin (henceforth chymotrypsin), a $25 \mathrm{kD}$ globular protein of 245 amino acids (Fig. 1). Analytes were added to the cis side of wild-type $\mathrm{FraC}(\mathrm{WtFraC}$ ) nanopores (Fig. 1a) containing a $1 \mathrm{M} \mathrm{KCl}, 15 \mathrm{mM}$ Tris base, $\mathrm{pH} 7.5$ solution, and an external potential was applied to the "working" electrode located in the trans compartment. Because WtFraC shows gating above approximately $+50 \mathrm{mV}$, but is stable at potentials as high as $-300 \mathrm{mV}$, a potential at which the lipid bilayer consisting of 1,2diphytanoyl-sn-glycero-3-phosphocholine becomes presumably unstable, we applied potentials between those limits. Addition of $1 \mu \mathrm{M}$ of endothelin 1 to the cis compartment did not provoke blockades at $+50 \mathrm{mV}$ (Fig. 1b) and up to $-300 \mathrm{mV}$. Since the constriction of $\mathrm{WtFraC}$ is lined with aspartic acid residues (Fig. 1a), we reasoned that the protonation of these residues at more acidic $\mathrm{pH}$ values should diminish the energy barrier for the translocation of endothelin 1 , which carries a net charge of -2 at $\mathrm{pH}$ 7. Simultaneously, a less negative endothelin 1 would also migrate more easily toward the trans electrode under negative applied potentials. Endothelin 1 blockades started to appear at $\mathrm{pH}$ 6.4 at $-50 \mathrm{mV}$ (Supplementary Fig. 1a), and their capture frequency increased linearly with decreasing the $\mathrm{pH}$ (Supplementary Fig. 1b). At $\mathrm{pH} 4.5(1 \mathrm{M} \mathrm{KCl}, 0.1 \mathrm{M}$ citric acid, $180 \mathrm{mM}$ Tris base), endothelin 1 blockades to $\mathrm{WtFraC}$ were observed at $-50 \mathrm{mV}$, but not at $+50 \mathrm{mV}$ (Table 1; Fig. 1b).

Encouraged by the effect of a more positive constriction under acidic conditions, we next investigated the capture of endothelin 1 with the D10R, K159E FraC ( $\mathrm{ReFraC})$ nanopore, a pore with arginine residues at its constriction, which we previously engineered for purposes of DNA analysis ${ }^{49}$. Conversely to $\mathrm{WtFraC}, \mathrm{ReFraC}$ is stable under positive applied potentials but displays gating at potentials of approximately $-50 \mathrm{mV}$. Consequently, we only applied voltages between -50 and $+200 \mathrm{mV}$ to ReFraC. Addition of $1 \mu \mathrm{M}$ endothelin 1 to the cis compartment elicited blockades at $\mathrm{pH} 7.5$ at $+50 \mathrm{mV}$ but not $-50 \mathrm{mV}$ (Table 1; Fig. 1b). Decreasing the $\mathrm{pH}$ to $4.5(1 \mathrm{M} \mathrm{KCl}, 0.1 \mathrm{M}$ citric acid, $180 \mathrm{mM}$ Tris base) led to an increase in capture frequency at

Table 1 Parameters of endothelin 1 and chymotrypsin captured with WtFraC and ReFraC

\begin{tabular}{|c|c|c|c|c|c|c|c|c|c|}
\hline & \multicolumn{4}{|l|}{ WtFraC } & & \multicolumn{4}{|l|}{ ReFraC } \\
\hline & \multicolumn{2}{|l|}{ pH 7.5} & \multicolumn{2}{|l|}{ pH 4.5} & & \multicolumn{2}{|l|}{ pH 7.5} & \multicolumn{2}{|l|}{ pH 4.5} \\
\hline & $\tau_{\text {on }}(\mathrm{ms})$ & $\tau_{\text {off }}(\mathrm{ms})$ & $\tau_{\text {on }}$ (ms) & $\tau_{\text {off }}(\mathrm{ms})$ & & $\tau_{\text {on }}(\mathrm{ms})$ & $\tau_{\text {off }}$ (ms) & $\tau_{\text {on }}(\mathrm{ms})$ & $\tau_{\text {off }}$ (ms) \\
\hline Endothelin $1(-50 \mathrm{mV})$ & - & - & $5.8 \pm 0.7$ & $5.6 \pm 2.0$ & Endothelin $1(+50 \mathrm{mV})$ & $1413.7 \pm 286.9$ & $3.3 \pm 2.2$ & $401.7 \pm 79.4$ & $8.5 \pm 1.8$ \\
\hline $\begin{array}{l}\text { Chymotrypsin } \\
(-100 \mathrm{mV})\end{array}$ & $4.4 \pm 1.9$ & $12.0 \pm 5.7$ & $9.6 \pm 2.5$ & $1.7 \pm 0.9$ & Chymotrypsin $(+200 \mathrm{mV})$ & $174.3 \pm 22.9$ & $0.2 \pm 0.1$ & $112.5 \pm 9.5$ & $1.3 \pm 0.7$ \\
\hline
\end{tabular}


a

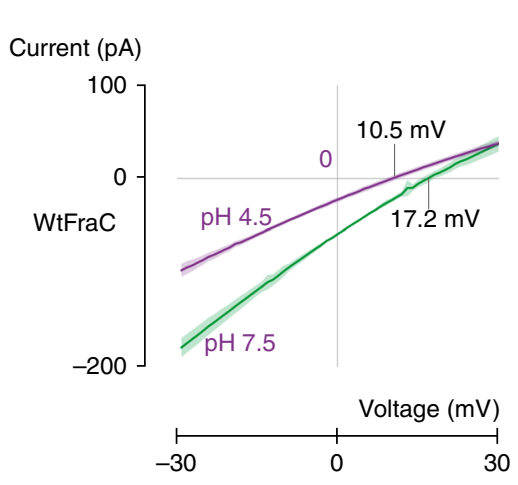

Current $(\mathrm{pA})$

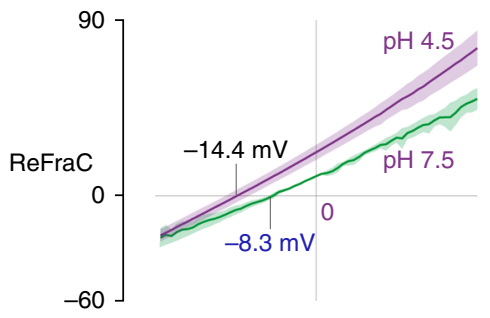

b

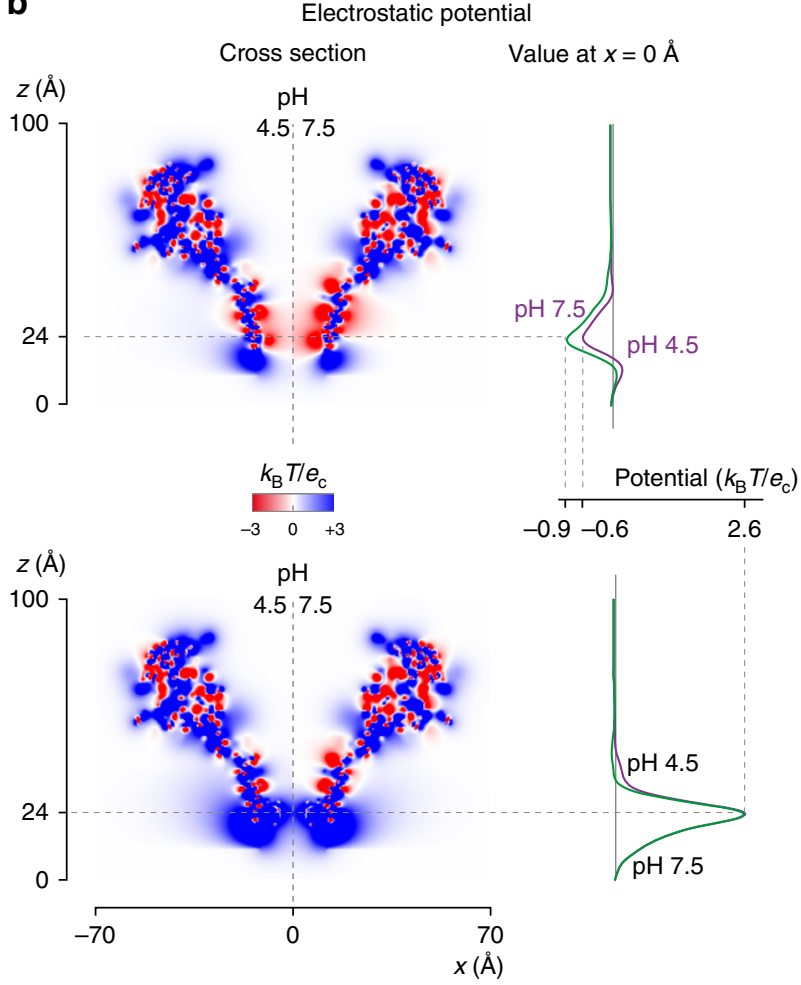

Fig. 2 Ion selectivity and electrostatic distribution of WtFraC and ReFraC. a Determination of the reversal potential shows that WtFraC and ReFraC are, respectively, cation- and anion-selective, as expected from the electrostatic potentials at their constrictions. All reversal potentials were measured under asymmetric salt conditions ( $467 \mathrm{mM} \mathrm{KCl}$ in trans and $1960 \mathrm{mM} \mathrm{KCl}$ in cis) and the ion selectivity determined using the Goldman-Hodgkin-Katz equation (Eq. 1 in the main text). The buffer contained $15 \mathrm{mM}$ Tris base at $\mathrm{pH} 7.5$ and $100 \mathrm{mM}$ sodium citrate at pH 4.5. b The averaged simulated electrostatic potentials reveal the negatively and positively charged constrictions of WtFraC and ReFraC, respectively. While for ReFraC lowering of the $\mathrm{pH}$ from 7.5 to 4.5 only had a small effect on the electrostatic potential, for WtFraC the peak value at the center of the constriction dropped by $37 \%$. All simulations were performed using $\mathrm{APBS}^{75}$ at $1 \mathrm{M} \mathrm{KCl}$, with the partial charge of each titratable residue adjusted according to their average protonation states with a modified version of the PDB2PQR software ${ }^{72}$. Residue $p K a$ values were estimated using PROPKA ${ }^{78,79}$. Detailed experiment procedures are given in Methods section. The envelopes behind every current-voltage curve represent their respective standard deviations obtained from three repeats

$+50 \mathrm{mV}$ (Table 1; Fig. 1b), despite the reduced electrophoretic mobility toward the trans electrode.

Next we tested chymotrypsin $(25 \mathrm{KDa}, \mathrm{pI}=8.75)$ as representative of a relatively large protein analyte. Protein blockades were only observed at negative applied potentials from $-50 \mathrm{mV}$ (Supplementary Fig. 2) and higher potentials in $\mathrm{pH} 7.5$ buffer ( $1 \mathrm{M} \mathrm{KCl}, 15 \mathrm{mM}$ Tris base). The residual current became homogeneous when we increased the potential to $-100 \mathrm{mV}$ (Table 1; Fig. 1c). Contrary to what we observed for endothelin 1, the capture frequency of chymotrypsin remained constant between $\mathrm{pH} 7.5$ and 5.5, and decreased by $\sim 50 \%$ when the $\mathrm{pH}$ was lowered to 4.4 (Supplementary Fig. 3). Using ReFraC at $\mathrm{pH}$ 7.5, we noticed only few blockades at high positive applied potentials but not at $-50 \mathrm{mV}$ (Table 1; Fig. 1c). Decreasing the $\mathrm{pH}$ to 4.5 led to an increase in capture frequency (Table 1; Fig. 1c). Notably, ReFraC showed often shallow gating events at negative applied potentials under acidic conditions as shown in Fig. 1c, bottom right. Taken together, both nanopores can capture analytes differing 10 -fold in molecular weight ( 2.5 vs. $25 \mathrm{kDa})$.

The charge of the constriction dictates the ion selectivity. To collect details of the ion transport across WtFraC and ReFraC pores, we measured the ion selectivity of $\mathrm{WtFraC}$ and ReFraC pores using asymmetric $\mathrm{KCl}$ concentrations on either side of the nanopore (1960 and $467 \mathrm{mM})$. The reversal potential $\left(V_{\mathrm{r}}\right)$, i.e., the potential at which the current is zero (Fig. 2a), was then used, together with the Goldman-Hodgkin-Katz equation, to calculate the ion selectivity $\left(P_{\mathrm{K}^{+}} / P_{\mathrm{Cl}^{-}}\right)$of both nanopores:

$$
\frac{P_{\mathrm{K}^{+}}}{P_{\mathrm{Cl}^{-}}}=\frac{\left[a_{\mathrm{Cl}^{-}}\right]_{\text {trans }}-\left[a_{\mathrm{Cl}^{-}}\right]_{\mathrm{cis}} e^{V_{\mathrm{r}} F / R T}}{\left[a_{\mathrm{K}^{+}}\right]_{\text {trans }} e^{V_{\mathrm{r}} F / R T}-\left[a_{\mathrm{K}^{+}}\right]_{\mathrm{cis}}},
$$

where $\left[a_{\mathrm{K}^{+} / \mathrm{Cl}^{-}}\right]_{\text {cis/trans }}$ is the activity of the $\mathrm{K}^{+}$or $\mathrm{Cl}^{-}$in the cis or trans compartments, $R$ the gas constant, $T$ the temperature, and $F$ the Faraday's constant. We found that the ion selectivity of FraC nanopores depends on the charge of the constriction, with WtFraC being strongly cation-selective $\left(P_{\mathrm{K}^{+}} / P_{\mathrm{Cl}^{-}}=3.64 \pm 0.37\right.$, $\mathrm{pH} 7.5)$ and ReFraC anion-selective $\left(P_{\mathrm{K}^{+}} / P_{\mathrm{Cl}^{-}}=0.57 \pm 0.04, \mathrm{pH}\right.$ 7.5). Here and throughout the manuscript, errors indicate the standard deviations obtained from three or more experiments.

To gain a better understanding of the effect of $\mathrm{pH}$ on ion selectivity, we used a computational approach to estimate the magnitude and distribution of electrostatic field generated by nanopores when surrounded by an electrolyte at $\mathrm{pH} 7.5$ and 4.5. The simulations showed that the constriction regions of WtFraC and ReFraC at the center of the nanopore exhibited highly negative and positive potentials, respectively (Fig. $2 \mathrm{~b}$ ). In $\mathrm{WtFraC}$, the lowering of the $\mathrm{pH}$ from 7.5 to 4.5 reduced the potential at the center of the constriction by $37 \%$ (from -0.87 to $-0.55 k_{\mathrm{B}} T / e_{c}$, with $1 k_{\mathrm{B}} T / e_{c}=25.6 \mathrm{mV}$ at $298 \mathrm{~K}$ ) in line with the $43 \%$ reduction of the ion selectivity of the nanopores $\left(P_{\mathrm{K}^{+}} / P_{\mathrm{Cl}^{-}}=2.11 \pm 0.23\right.$ at $\mathrm{pH}$ 4.5) and confirming that the ionic transport across the nanopore is dominated by the charge of the constriction. Interestingly, at $\mathrm{pH} 4.5$ the ion selectivity of ReFraC increased by $37 \%$ compared to $\mathrm{pH} 7.5$ (Fig. 2a) despite the roughly 
a
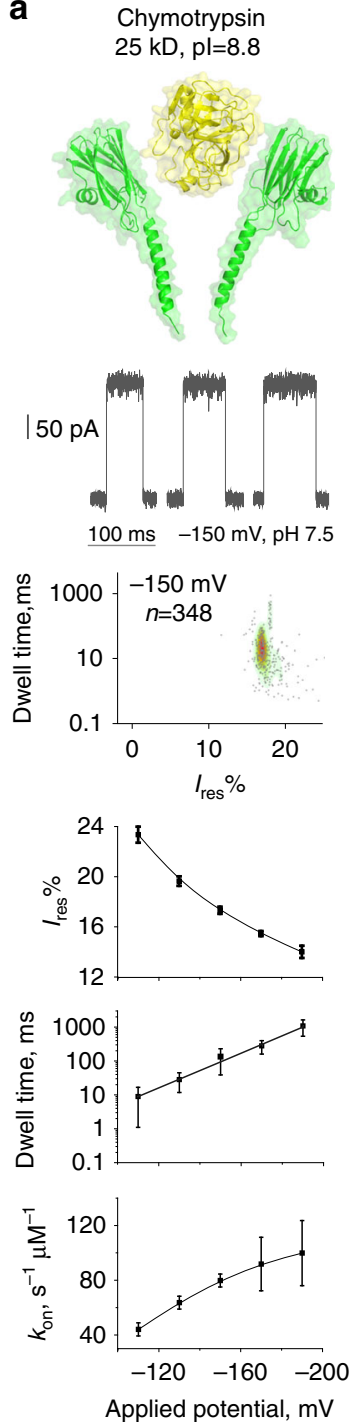

b

$\beta 2$-microglobulin $11.6 \mathrm{kD}, \mathrm{pl}=5.6$
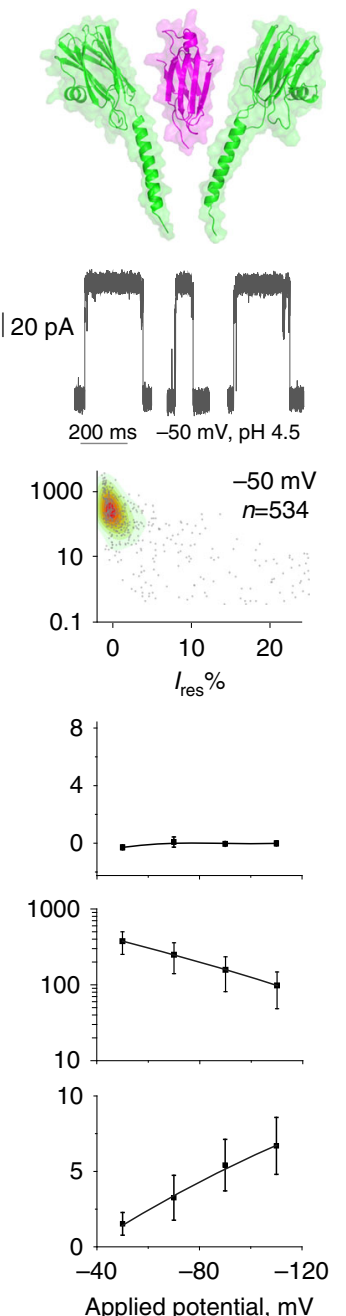

c $6.2 \mathrm{kD}, \mathrm{pl}=4.5$
.
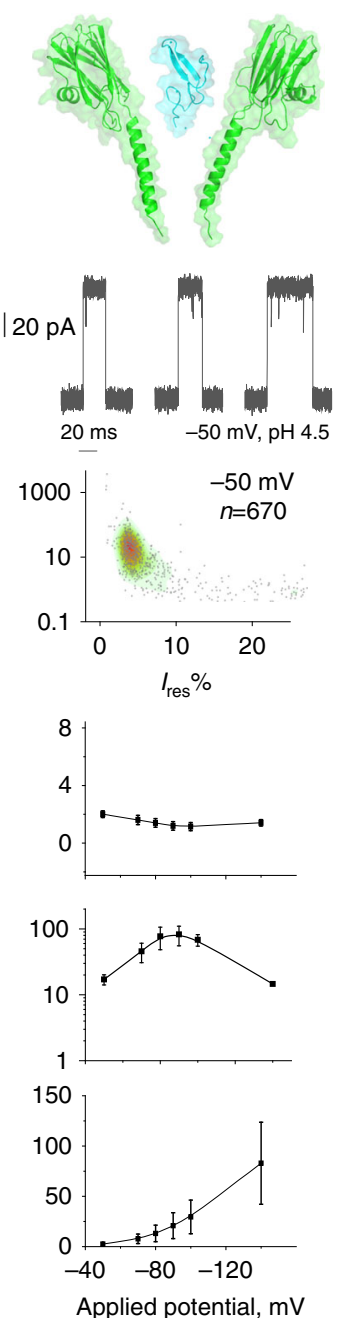

d

Endothelin 1 $2.5 \mathrm{kD}, \mathrm{pl}=4.2$
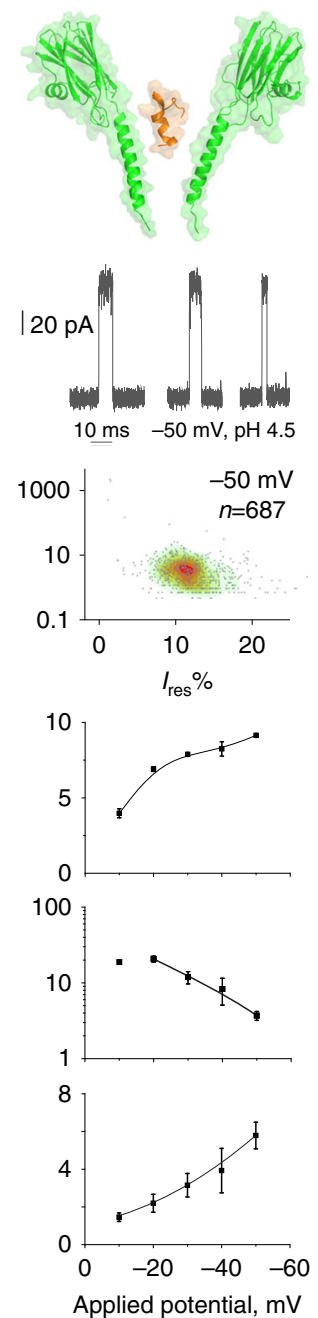

Angiotensin I
$1.3 \mathrm{kD}, \mathrm{pl}=7.9$
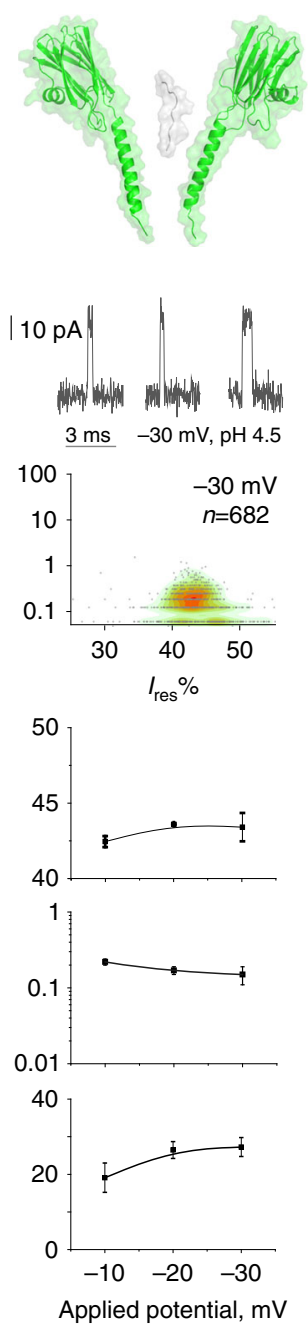

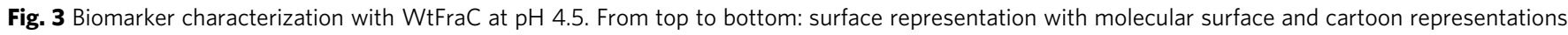
(PyMOL) of the biomarker, a representative trace obtained under the indicated applied potential, a heatplot depicting the dwell time distribution vs. $I_{\text {res} \% ~}$ at

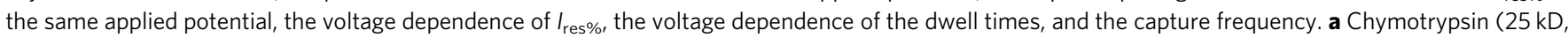
PDB: 5CHA), b 32 -microglobulin (11.6 kD, PDB: 1LDS), c human EGF (6.2 kD, PDB: 1JL9), d endothelin 1 (2.5 kD, PDB: 1EDN), and e angiotensin I (1.3 kD), respectively. Angiotensin I is depicted as a random structure drawn with PyMOL. The concentrations of the biomarkers were: 200 nM for chymotrypsin, $200 \mathrm{nM}$ for $\beta 2$-microglobulin, $2 \mu \mathrm{M}$ for human EGF, $1 \mu \mathrm{M}$ for endothelin 1, and $2 \mu \mathrm{M}$ for angiotensin I, respectively. Isoelectric points of biomarkers are obtained from literatures or with the online calculation tool PepCalc. Error bars represent the standard deviation obtained from at least 3 repeats and at least 300 events for each repeat. The voltage dependencies of capture frequencies were fitted to quadratic functions. With the exception of EGF, voltage dependencies of dwell times were fitted to single exponentials. All remaining data were fitted using a B-spline function (Origin 8.1). All recordings were collected with $50 \mathrm{kHz}$ sampling rate and $10 \mathrm{kHz}$ low-pass Bessel filter. Detailed numbers and analysis for each data point could be found in the supporting information (Supplementary Figs. 11-15 and Supplementary Table 7)

constant electrostatic potential of the nanopore constriction (Fig. 2b). Presumably, when the charge at the constriction does not change, the ion selectivity can still be influenced by the protonation state of other residues located on the nanopore surface (Fig. 2b).

Electro-osmotic flow promotes polypeptides entry into FraC. The entry of the proteins inside FraC may occur by passive diffusion, and by the combined effect of the electrophoretic force on the polypeptide charges and electro-osmotic force, the latter being the results of the EOF, that is the directional flux of water across the nanopore. The strength and direction of the EOF inside a nanopore depends on its shape, charge, the nanopore asymmetry, and is related to the ion selectivity ${ }^{21,25,26,51-53}$. An estimate of the direction and the magnitude of the water flux $\left(J_{w}\right)$ due to the ion selectivity can be obtained using the following equation ${ }^{52}$ :

$$
J_{w}=N_{w} \frac{I}{e_{c}}\left(\frac{1-P_{\mathrm{K}^{+}} / P_{\mathrm{Cl}^{-}}}{1+P_{\mathrm{K}^{+}} / P_{\mathrm{Cl}^{-}}}\right),
$$

where $N_{w}$ is the number of water molecules per ion (hydration shell), $I$ the ionic current, $e_{c}$ the elementary charge, and $P_{\mathrm{K}^{+}} / P_{\mathrm{Cl}^{-}}$ the ion selectivity. Note that the equation above likely underestimates the water flux, as it does not take the movement of the electrical double layer into account. Using a value of 10 water molecules per ion ${ }^{26}, 52$, water fluxes and velocities can be estimated (Supplementary Table 1). In WtFraC, water flows from cis 
a
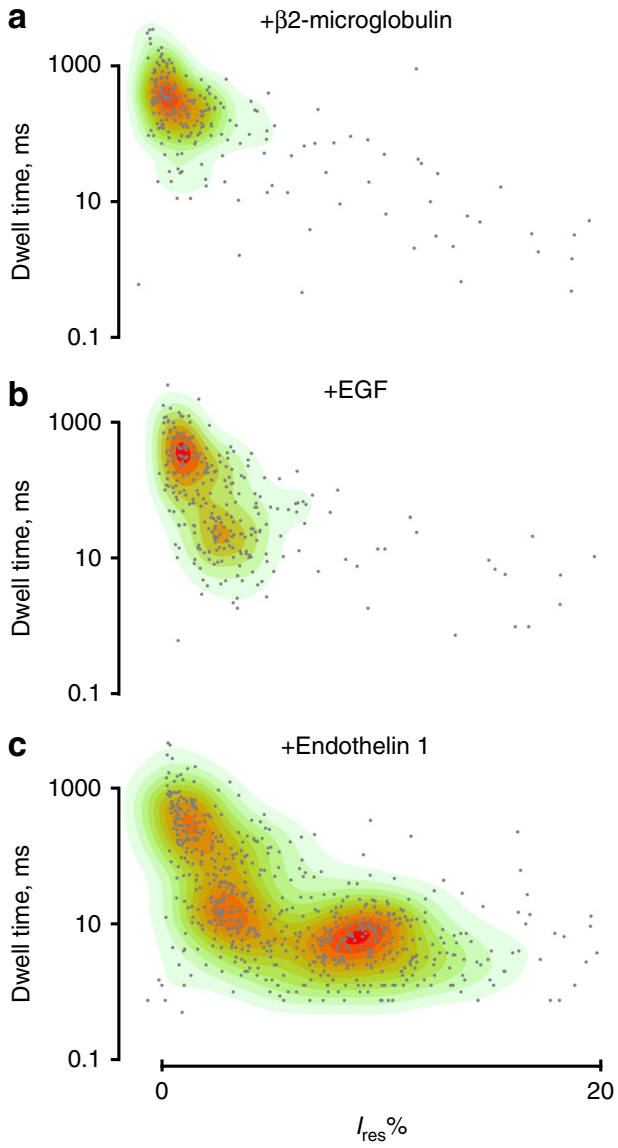

d

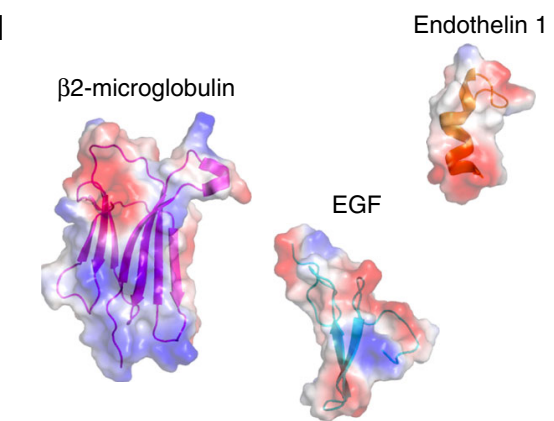

Fig. 4 Discrimination of a biomarker mixture with WtFraC at $\mathrm{pH}$ 4.5. A single WtFraC nanopore was obtained in a buffer at pH $4.5(1 \mathrm{M} \mathrm{KCl}, 0.1 \mathrm{M}$ citric acid, $180 \mathrm{mM}$ Tris base) under a $-50 \mathrm{mV}$ applied potential. About $200 \mathrm{nM}$ of $\beta 2$-microglobulin was initially added to the cis compartment (a),

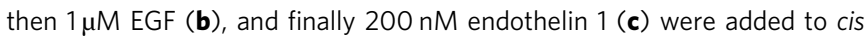
compartment. d Crystal structure of $\beta 2$-microglobulin, EGF, and endothelin 1 mixture created with PyMOL colored according to their vacuum electrostatics

to trans at negative applied potentials and the reduced ion selectivity at $\mathrm{pH} 4.5$ results in a flux reduction of $\sim 59 \%$ (from $6.08 \times 10^{9}$ to $2.48 \times 10^{9}$ hydrated water molecules per second at $-50 \mathrm{mV}$ ). The net water flux in $\mathrm{ReFraC}$, on the other hand, flows from cis to trans at positive applied potentials and increases by $\sim 51 \%$ when the $\mathrm{pH}$ is decreased (from $1.37 \times 10^{9}$ at $\mathrm{pH} 7.5$ to $2.08 \times 10^{9}$ at $\left.+50 \mathrm{mV}\right)$. These data suggest that the EOF has a dominant role in the capture of both proteins and peptides, as both chymotrypsin $(25 \mathrm{kDa}, \mathrm{pI}=8.8$, net positive charge $)$ and endothelin 1 ( $2.5 \mathrm{kDa}$, formal charge -2$)$ enter WtFraC and ReFraC only when the direction of the EOF is from cis to trans, irrespectively from the charge of the biomarker or the sign of the applied potential at the trans electrode (negative for $\mathrm{WtFraC}$ and positive for ReFraC).

Biomarker detection with the WtFraC nanopore. After assessing the capture of chymotrypsin $(25 \mathrm{kD}, 245$ amino acids) and endothelin 1 ( $2.5 \mathrm{kD}, 21$ amino acids), biomarkers for pancreatic cysts $^{54}$ and bronchiolitis obliterans ${ }^{55}$, respectively, we used the $\mathrm{WtFraC}$ nanopores to detect a larger range of peptide and protein biomarkers including $\beta 2$-microglobulin, a $11.6 \mathrm{kDa}$ (99 amino acids) biomarker for peripheral arterial disease ${ }^{56}$, human EGF, a $6.2 \mathrm{kDa}$ (53 amino acids) biomarker for chronic kidney disease ${ }^{57}$, and angiotensin $\mathrm{I}$, a $1.3 \mathrm{kD}$ (10 amino acids) biomarker for hypertensive crisis (Fig. 3) ${ }^{58}$. At pH 7.5, $\beta 2$-microglobulin and EGF entered the WtFraC only at high negative applied potentials (>-200 mV; Supplementary Figs. 4, 5). The entry of endothelin 1 $(2.5 \mathrm{kD}, \mathrm{pI}=4.16)$ into FraC nanopores could not be observed at potentials up to $-300 \mathrm{mV}$ (Supplementary Fig. 6), while the blockade of angiotensin I $(1.3 \mathrm{kD}, \mathrm{pI}=7.93)$ could not be assessed as the peptide induced blockades that were too fast to be analyzed (Supplementary Fig. 7). By contrast, at $\mathrm{pH} 4.5$ all biomarkers entered the FraC nanopores. Thus all biomarkers were assessed under negative applied potentials at $\mathrm{pH} 4.5$ with the exception of chymotrypsin.

Protein translocation might deform FraC transmembrane helices. It is generally accepted ${ }^{59-63}$ and experimentally shown ${ }^{35}$ that the voltage dependence of the dwell time of a molecule can report whether it translocates a nanopore. If a molecule translocates through a nanopore, increasing the electrophoretic or electro-osmotic driving force reduces its residence time inside the nanopore (i.e., the dwell time). By contrast, if molecules do not translocate the nanopore, the dwell time will increase with the applied potential. Under this assumption, at $\mathrm{pH} 4.5$ biomarkers entered and translocated $\mathrm{WtFraC}$ nanopores. The voltage dependence of chymotrypsin (Fig. 3a) suggests that this biomarker does not translocate through WtFraC nanopores. This is expected, giving that the protein is larger than the transmembrane constriction of the nanopore (Fig. 3a). Accordingly, the $I_{\text {res }}$ $\%$, which refers to percent ratios between the blocked and open pore ionic currents, of protein blockades decreased with the applied potential, suggesting that the protein is pushed further inside the nanopore as the EOF is increased. As a folded protein $\beta 2$-microglobulin is larger than the constriction of $\mathrm{WtFraC}$ (Fig. 3b). Surprisingly, however, we found that the dwell times of the blockades decreased with the potential, suggesting that the protein translocates through the nanopore. Translocation of $\beta 2$ microglobulin would require that either the protein or the transmembrane domain of FraC unfolds or deforms. The $I_{\text {res\% }}$ was near zero, suggesting a tight interaction between $\beta 2$-microglobulin and the nanopore walls. Further, the $I_{\text {res\% }}$ remained constant over the applied potential, which is consistent with a protein remaining folded within the nanopore ${ }^{64,65}$. Together, these findings suggest that the transmembrane region of the nanopore deforms during the translocation of folded $\beta 2$-microglobulin molecules. This interpretation is consistent with our previous study in which we observed transient remodeling of FraC transmembrane region during the translocation of doublestranded DNA through the nanopore ${ }^{49}$.

Threshold potential and stretched polypeptides. The bi-modal voltage dependency of dwell times observed with EGF and endothelin 1 (Fig. 3c, d) suggests that these proteins translocate above a certain potential $(-90 \mathrm{mV}$ and $-20 \mathrm{mV}$, respectively). This interpretation is corroborated by a previous study where the bi-modal voltage dependency of DHFR blockades to ClyA 
a

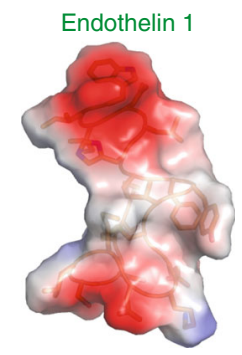

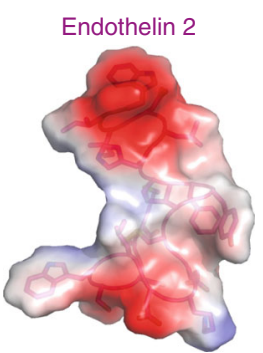

b

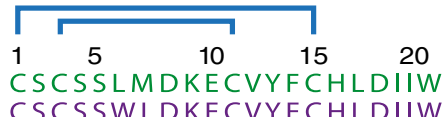

ET-1 CSCSSLMDKECVYFCHLDIIW
ET-2 CSCSSWLDKECVYECHLDIIW

\begin{tabular}{ccr}
\hline & ET-1 & \multicolumn{1}{c}{ ET-2 } \\
\hline$I_{\text {res }} \%$ & $8.9 \pm 0.1$ & $6.1 \pm 1.4$ \\
Dwell time $(\mathrm{ms})$ & $5.6 \pm 2.0$ & $19.0 \pm 5.3$ \\
\hline
\end{tabular}

C

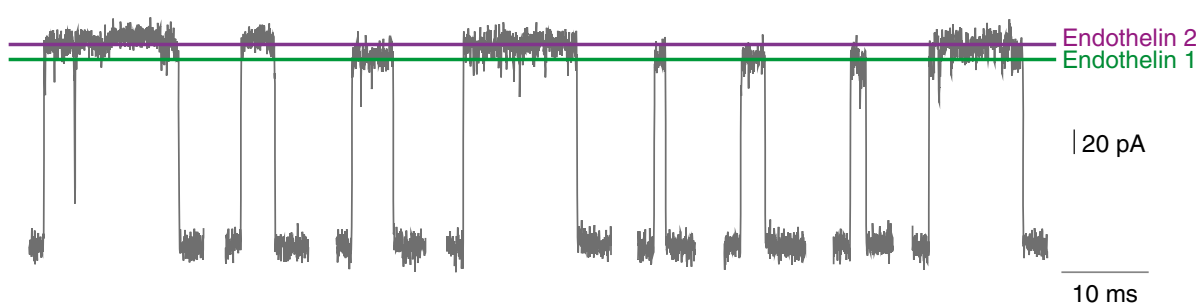

d

Endothelin 1

Amplitude (SD), pA
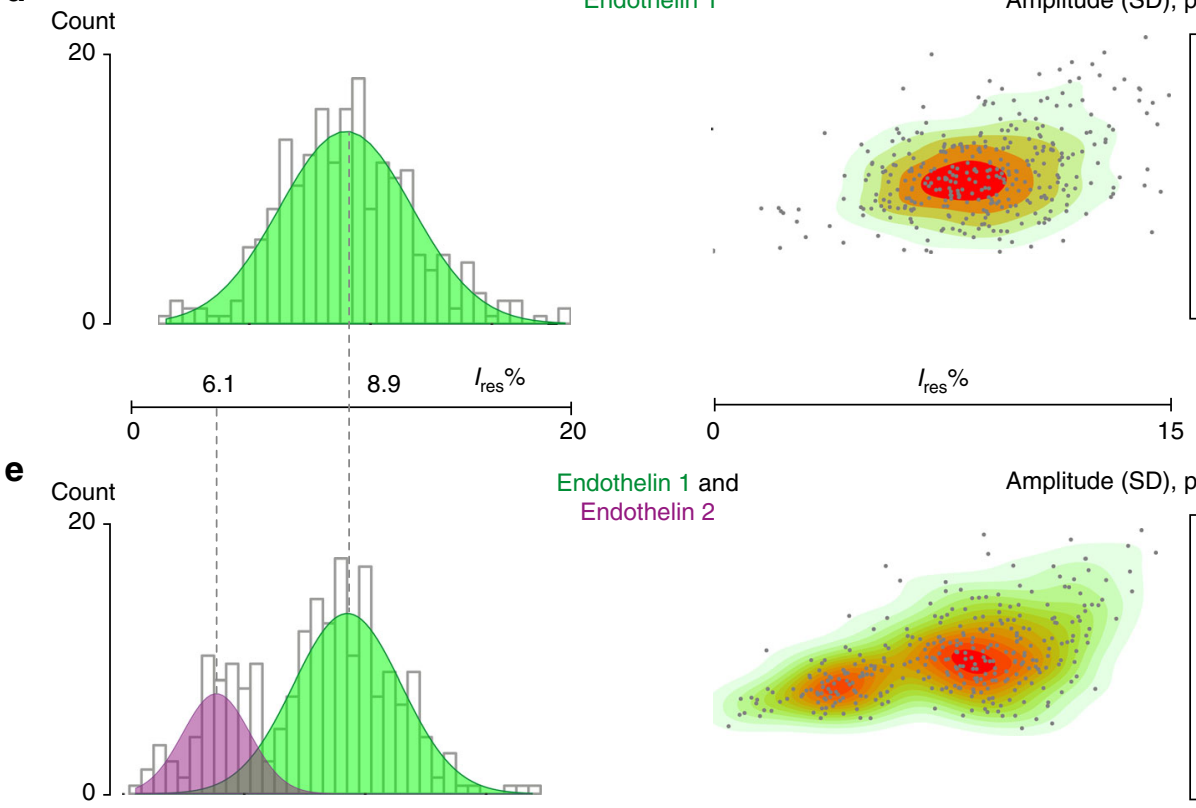

Endothelin 1 and

Endothelin 2

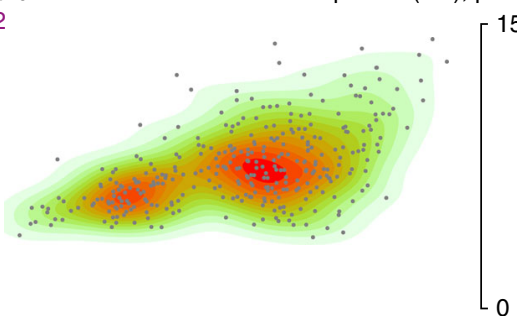

Fig. 5 Discrimination of endothelin 1 and 2 with WtFraC at pH 4.5. a Molecular surface representation of endothelin 1 (PDB: 1EDN) and endothelin 2 (homology model from endothelin 1, PyMOL) using electrostatic coloring (PyMOL). b Above: amino-acid sequences of endothelin 1 and 2. Blue lines indicate the disulfide bridges in each polypeptide. Below: $I_{\text {res } \%}$ and dwell time for endothelin 1 and endothelin 2 blockades at $-50 \mathrm{mV}$ in pH 4.5 buffer $(1 \mathrm{M}$ $\mathrm{KCl}, 0.1 \mathrm{M}$ citric acid, $180 \mathrm{mM}$ Tris base). Standard deviations are calculated from three experiments (Supplementary Fig. 16). c Representative endothelin 1 and endothelin 2 blockades to the same FraC nanopore under $-50 \mathrm{mV}$ applied potential. d Histogram (left) of residual currents provoked by $2 \mu \mathrm{M}$ endothelin 1 and corresponding heatplot depicting the standard deviation of the current amplitude vs. Ires\% (right). e Same as in $\mathbf{d}$ but after addition of $8 \mu \mathrm{M}$ endothelin 2 to the same pore revealing a second population. Graphs were created with custom R scripts. All recordings were conducted with $50 \mathrm{kHz}$ sampling rate and $10 \mathrm{kHz}$ Bessel low-pass filter

nanopores was shown to correspond to a voltage threshold potential for the translocation of the protein across the nanopore $^{36}$. Interestingly, the $I_{\text {res\% }}$ of endothelin 1 increased with the applied potential, suggesting that this polypeptide may be stretched by the increased EOF through the nanopore. This observation is in accordance with previous studies reporting that proteins and polypeptides can be stretched by high applied potentials 24,66 . If confirmed, this is an important finding for protein-sequencing applications, because it suggests that the EOF across the nanopore can linearize a polypeptide during translocation. Finally, angiotensin 1 translocated at all potentials tested (Fig. 3e). The dwell time of angiotensin 1 was close to the limit of detection, thus most likely angiotensin 1, an oligopeptide of just 10 amino acids, represents the limit of oligopeptide detection using FraC nanopores.

The capture frequency of all biomarkers increased with the applied potential. Previous work with DNA revealed that the entry of a polymer inside a nanopore can be diffusion-limited, i.e., all molecules colliding with the nanopore are captured or reaction-limited, i.e., only a fraction of molecules colliding with the nanopore are captured. For a diffusion-limited entry, polypeptide capture is expected to vary linearly with the applied voltage bias. For a reaction-limited entry, the relation should be exponential $^{67,68}$. Our data could not be fitted to either linear or 
exponential regressions (Fig. 3), suggesting that the entry and confinement of polypeptides inside FraC might be influenced by a complex interplay between the electro-osmotic, electrophoretic, and electrostatic forces inside the nanopores. By contrast, the voltage dependence of the dwell times of the polypeptide fitted well to exponential regressions (Fig. 3), indicating that the escape from the nanopore, either from the cis side (Chymotrypsin and EGF below $-90 \mathrm{mV}$ ) or trans side $(\beta 2$-microglobulin, endothelin 1, angiotensin I, and EGF above $-90 \mathrm{mV}$ ), is a reaction-limited process.

Recognition of peptide and protein biomarkers. Differentially sized oligo- and polypeptides as well as proteins were easily distinguished using several parameters, including the residual current and the duration of the current blockades (Fig. 3). Using identical conditions, and the same applied voltage, we discriminated $\beta 2$-microglobulin, EGF as well as endothelin 1 in a mixture (Fig. 4). At $-50 \mathrm{mV}$ applied potential, almost every blockade elicited by $\beta 2$-microglobulin, EGF, and endothelin 1 could be distinguished. Most likely, the conical shape of FraC nanopores is instrumental for recognizing folded polymers, which presumably penetrate and interact at different heights with the lumen of the nanopore. In order to challenge our experimental system, we sought to identify even more similar analytes. We chose endothelin 1 and endothelin 2, near-isomeric polypeptides differing in 1 out of 21 amino acids being otherwise structural isomers (Fig. 5a, b, also note that leucine 6 in endothelin 1 is at position 7 in endothelin 2). Remarkably, at $-50 \mathrm{mV}$, we observed distinguishable blockades with unique $I_{\text {res\% }}$ and dwell times (Fig. $5 b, c)$ for endothelin $1\left(I_{\text {res\% }}: 8.9 \pm 0.1 \%\right.$, dwell time $5.6 \pm$ $2.0 \mathrm{~ms}, N=3, n=600)$ and endothelin $2(6.1 \pm 1.4 \%$, dwell time $19.0 \pm 5.3 \mathrm{~ms}, N=3, n=384)$. This enabled their identification on an individual blockade level already (Fig. 5c). When we added consecutively first $2 \mu \mathrm{M}$ endothelin 1 (Fig. 5d) and then $8 \mu \mathrm{M}$ endothelin 2 to the same pore (Fig. 5e), we could also observe two distinct populations by plotting the standard deviation of the amplitude of events over their corresponding $I_{\text {res\%. The two }}$ disulfide bonds in both endothelins likely allow them to maintain a partially folded structure also during translocation across the nanopore. Thus, the different current blockades could arise from the additional bulky tryptophan residue in endothelin 2 (Fig. 5a). By contrast, detection of smaller and unfolded oligopeptides is more challenging. Angiotensin 2, which lacks two amino acids at the C-terminal of angiotensin 1 and is expected to translocate unfolded through the nanopore, showed very short event $(<100$ $\mu$ at $50 \mathrm{kHz}$ sampling rate). Most likely, the sequence analysis of unfolded oligopeptides will require additional improvements such as a smaller nanopore or the use of enzymes to reduce the translocation speed across the nanopore.

\section{Discussion}

In this work, we show that FraC nanopores can be used as a sensor in single-molecule proteomic analysis. In the simplest implementation of nanopore proteomics, proteins are recognized amino acid-by-amino acid, as they translocate linearly through a nanopore. Notably, since the sequence of proteins and peptides in an organism is known from genomic analysis, a protein sequence might be obtained by recognizing only a subset of amino acids ${ }^{69}$. Alternatively, folded proteins and peptides could be recognized, as they reside inside the nanopore and matched to previously established blockades, i.e., matching a fingerprint-like blockade to a database of known blockades. The challenges of folded and unfolded recognition, however, are different. In folded protein recognition, the transport dynamics of analyte peptides and proteins across the nanopore are not critical, and analytes are recognized as they reside in vestibule of the nanopore. Here we showed that differentially sized oligo- and polypeptides as well as proteins were easily distinguished using several parameters including residual current and duration of the current blockade (Figs. 3, 4). Remarkably, the nanopore was also able to distinguish between blockades of endothelin 1 and endothelin 2, whose amino acid sequence only differs by a single amino acid (a tryptophan, Fig. 5). However, despite the sensitivity of nanopore currents, it is unlikely that all the proteins in a proteome will elicit a specific signal, and a biological sample will most likely require a pre-purification and/or concentration step.

An important issue in folded protein analysis is the detection of low-abundance proteins. Since the nanopore approach is a singlemolecule technique, in principle the detection of low-abundance proteins is merely an issue of waiting until the target analytes are captured by the nanopore. In practice, however, the experiment should be carried out within a specific time window. Considering that 10-100 events are required to identify and quantify a specific analyte, and assuming a running time of $1000 \mathrm{~s}$ (about $15 \mathrm{~min}$ ), the target analyte should be captured with a frequency of $0.1-0.01$ events per second. This corresponds to a concentration threshold limit of $\sim 1 \mathrm{nM}$ for the biomarkers sampled here. Because the concentration of proteins in blood can be much lower, the sensitivity of this technique has to be increased. This could be done by using arrays of nanopores. For example an array of 1000 nanopores would allow sampling analytes in the $\mathrm{pM}$ range. Alternatively, binding elements such as aptamers or antibodies could be conjugated to the nanopore or to the lipid bilayer to increase the local concentration of analytes near the nanopore ${ }^{23}$. Finally, in analogy to most proteomic techniques, target analytes could be either purified or enriched prior analysis. Crucially, nanopore sensors only require nanoscale volumes to be sampled. Thus, the theoretical detection limit of the nanopore approach is just a few thousand copies of biomarkers collected from a biological sample.

In unfolded protein recognition, the direction of translocation of the polypeptide across the nanopore must be tightly controlled. In particular, the back movement of the polymer should be avoided, and the polypeptide should be stretched to allow addressing individual amino acids. Unlike DNA, however, polypeptides do not have a uniform charge and the electric field cannot be used to stretch or control the translocation across the nanopore. Therefore, the EOF must be used as the driving force for the nanoscale transport across a nanopore. However, since a polypeptide chain contains both positively and negatively charged amino acids, the electro-osmotic force should be higher than the electrophoretic force during translocation. An additional complication is that the EOF is generated by the fixed charge of the inner walls of the nanopore, which in turn might prevent or retard the translocation of amino acids through electrostatic interactions. In this work, we showed that at $\mathrm{pH} 7.5$ none of the biomarkers we tested, most of which were negatively charged, could translocate across the $\mathrm{WtFraC}$ nanopore. In contrast, at $\mathrm{pH}$ 4.5 all the polypeptides smaller than the nanopore constriction translocated the nanopore. Since the EOF through WtFraC is reduced by $\sim 60 \%$ upon lowering the $\mathrm{pH}$ to 4.5 , it is likely that polypeptide translocation across the nanopore is allowed by the attenuated electrostatic potential of the constriction (reduced by $\sim 40 \%$ in the same $\mathrm{pH}$ range) combined with the weaker opposing electrophoretic force on the partially protonated acidic amino acids (aspartate and glutamate) migrating toward the negative trans electrode. In turn, these findings suggest that at $\mathrm{pH} 4.5$, the constriction of WtFraC maintains a sufficient negative charge to induce a cis to trans EOF at negative applied potentials, while allowing the translocation of the negatively charged polypeptides across the nanopore against the applied potential. Although 
individual amino acids could not be identified on-the-fly during translocation, we showed that differences by just one bulky tryptophan residue in a small biomarker can be observed (Fig. 5). Therefore, if the speed of transport of a polypeptide can be controlled, for example, by the use of enzymes, it might be possible that FraC nanopores will allow the identification of specific sequence features in translocating polypeptides.

\section{Methods \\ Chemicals. $\alpha$-Chymotrypsin (from bovine pancreas, $\geq 85 \%$, C4129), $\beta 2$-micro-} globulin (from human urine, $\geq 98 \%$, M4890), endothelin 1 ( $\geq 97 \%$, E7764), endothelin $2(\geq 97 \%$, E9012), angiotensin I ( $\geq 90 \%$, A9650), pentane ( $\geq 99 \%, 236,705)$, hexadecane (99\%, H6703), Trizma hydrochloride (SLBG8541V), Trizma base (SLBK4455V), N,N-Dimethyldodecylamine N-oxide (LADO, $\geq 99 \%, 40,234$ ), and $n$-Dodecyl $\beta$-D-maltoside (DDM, $\geq 98 \%, \mathrm{D} 4641$ ) were obtained from SigmaAldrich. Human EGF ( $\geq 98 \%$, CYT-217) was obtained from PROSPEC. 1,2diphytanoyl-sn-glycero-3-phosphocholine (DPhPC, 850,356P) and sphingomyelin (Brain, Porcine, 860,062) were purchased from Avanti Polar Lipids. Potassium chloride ( $\geq 99 \%$, BCBL9989V) was bought from Fluka. Citric acid ( $\geq 99 \%$, A0365028) was obtained from ACROS. All polypeptide biomarkers and chemicals were used without further purification. About $15 \mathrm{mM}$ Tris base, $\mathrm{pH} 7.5$ buffer used in this study was prepared by dissolving $1.902 \mathrm{~g}$ Trizma $\mathrm{HCl}$ and $0.354 \mathrm{~g}$ Trizma Base in 11 water (Milli-Q, Millipore, Inc.)

FraC monomer expression and purification. A gene containing FraC with a Cterminus 6-His tag was cloned into a pT7-SC1 ${ }^{70}$ expression plasmid using $\mathrm{NcoI}$ and HindIII restriction digestion sites. For expression, the plasmid was transferred into E.cloni EXPRESS BL21(DE3) competent cell by electroporation. Transformants were harvested from the LB agar plate containing $100 \mathrm{mg} / \mathrm{l}$ ampicillin after overnight incubation at $37^{\circ} \mathrm{C}$, and inoculated into $200 \mathrm{ml}$ fresh liquid 2-YT media with $100 \mathrm{mg} / \mathrm{l}$ ampicillin. The cell culture was grown at $37^{\circ} \mathrm{C}$, with $220 \mathrm{rpm}$ shaking to an optical density at $600 \mathrm{~nm}$ of 0.8 after which $0.5 \mathrm{mM}$ IPTG was added to induce expression. The temperature was lowered to $25^{\circ} \mathrm{C}$ and the bacterial culture was allowed to grow for $12 \mathrm{~h}$. Cells were harvested by centrifugation for $30 \mathrm{~min}(2000 \times \mathrm{g})$ at $4{ }^{\circ} \mathrm{C}$. Cell pellets were stored at $-80^{\circ} \mathrm{C}$. About $50-100 \mathrm{ml}$ of cell culture pellet was thawed at room temperature, resuspended with $30 \mathrm{ml}$ lysis buffer ( $15 \mathrm{mM}$ Tris base $\mathrm{pH} 7.5,1 \mathrm{mM} \mathrm{MgCl} 2,4 \mathrm{M}$ Urea, $0.2 \mathrm{mg} / \mathrm{ml}$ lysozyme, and 0.05 units $/ \mathrm{ml}$ DNase) and mixed vigorously with a vortex shaker for $1 \mathrm{~h}$. In order to fully disrupt the cells, the suspension was sonicated for $2 \min$ (duty cycle $10 \%$, output control 3 using a Branson Sonifier 450). The crude lysate was then centrifuged at $5400 \times \mathrm{g}$ for $20 \mathrm{~min}$ at $4^{\circ} \mathrm{C}$. The supernatant (containing FraC monomers) was transferred to a $50 \mathrm{ml}$ falcon tube containing a $100 \mu \mathrm{l}$ of Ni-NTA resin (Qiagen, stored at $4{ }^{\circ} \mathrm{C}$, well mixed before pipetting out $100 \mu \mathrm{l}$ ), which was prewashed with $3 \mathrm{ml}$ of washing buffer $(10 \mathrm{mM}$ imidazole, $150 \mathrm{mM} \mathrm{NaCl}, 15 \mathrm{mM}$ Tris base, $\mathrm{pH}$ 7.5), and incubated at room temperature for $1 \mathrm{~h}$ with gentle mixing. The resin was spun down at $2000 \times g$ for $5 \mathrm{~min}$ at $4^{\circ} \mathrm{C}$. Most of the supernatant was discarded and the pellet containing the Ni-NTA resin within $\sim 5 \mathrm{ml}$ of buffer was transferred to a Micro Bio-Spin column (Bio-Rad) at room temperature. The NiNTA beads were washed with $10 \mathrm{ml}$ wash buffer and the protein was eluded with $500 \mu \mathrm{l}$ of $300 \mathrm{mM}$ imidazole. Protein concentration was determined with NanoDrop 2000 UV-Vis Spectrophotometer (Thermo Scientific). The monomers were stored at $4{ }^{\circ} \mathrm{C}$

Preparation of sphingomyelin-DPhPC liposomes. About $20 \mathrm{mg}$ sphingomyelin (Brain, Porcine, Avanti Polar Lipids) was mixed with $20 \mathrm{mg}$ of DPhPC (Avanti Polar Lipids) and dissolved in $4 \mathrm{ml}$ pentane (Sigma-Aldrich) containing $0.5 \% \mathrm{v} / \mathrm{v}$ ethanol. This lipid mixture was placed in a round flask and rotated slowly near a hair dryer to disperse the lipid well around the wall. The flask was kept open at room temperature for another $30 \mathrm{~min}$ to let the solvent evaporate completely. The lipid film deposited on the flask was then resuspended with $4 \mathrm{ml}$ of buffer $(150 \mathrm{mM}$ $\mathrm{NaCl}, 15 \mathrm{mM}$ Tris base, $\mathrm{pH}$ 7.5) by using a sonication bath for $5 \mathrm{~min}$. The final liposome solution concentration was $10 \mathrm{mg} / \mathrm{ml}$ and stored at $-20^{\circ} \mathrm{C}$.

Oligomerization of FraC. Frozen liposomes were sonicated after thawing and mixed with monomeric $\mathrm{FraC}$ in a lipid:protein mass ratio 10:1. The mixture was sonicated in sonication bath $\sim 30 \mathrm{~s}$ and then kept at $37^{\circ} \mathrm{C}$ for $30 \mathrm{~min}$. The proteoliposome was solubilized with $0.6 \%$ LDAO (N,N-Dimethyldodecylamine N-oxide, $5 \% \mathrm{w} / \mathrm{v}$ stock solution in water), then transferred to a $50 \mathrm{ml}$ falcon tube and diluted 20 times with buffer ( $150 \mathrm{mM} \mathrm{NaCl}, 15 \mathrm{mM}$ Tris base, $\mathrm{pH} 7.5,0.02 \% \mathrm{DDM})$. About $100 \mu \mathrm{l}$ of pre-washed Ni-NTA resin (Qiagen) was added to the diluted protein/liposome mixture. After incubation with gentle shaking for $1 \mathrm{~h}$, the beads were loaded to column (Micro Bio-Spin, Bio-Rad) and washed with $10 \mathrm{ml}$ buffer $(150 \mathrm{mM} \mathrm{NaCl}, 15 \mathrm{mM}$ Tris base, $\mathrm{pH}$ 7.5). FraC oligomers were eluted with $300 \mu \mathrm{l}$ elution buffer (200 mM EDTA, $75 \mathrm{mM} \mathrm{NaCl}, 7.5 \mathrm{mM}$ Tris base, $\mathrm{pH} 8,0.02 \%$ DDM). Oligomers are stable for several months at $4{ }^{\circ} \mathrm{C}$.
Simulation of the electrostatic potential. In order to understand the effect of $\mathrm{pH}$ changes on ion selectivity, we sought to simulate the magnitude and distribution of the electrostatic field created by the FraC nanopore. A well-established model for calculating such electrostatic potentials is the Poisson-Boltzmann equation (PBE)

$$
\nabla \cdot[\epsilon(\mathbf{r}) \nabla \phi(\mathbf{r})]+\frac{1}{\epsilon_{0}} \rho^{f}(\mathbf{r})+\frac{1}{\epsilon_{0}} \sum_{i=1}^{n} q_{i} c_{i}^{0} e^{-\frac{q_{i} \phi(\mathbf{r})}{k_{\mathrm{B}} T}}=0,
$$

where $\phi(\mathbf{r})$ is the electrostatic potential, $\epsilon(\mathbf{r})$ the relative permittivity, and $\rho^{f}(\mathbf{r})$ the distribution of fixed atomic charges, which are all dependent on positional vector $\mathbf{r}$. The symbols $\epsilon_{0}, k_{\mathrm{B}}$, and $T$ represent the permittivity of free space, the Boltzmann constant, and the temperature in kelvins, respectively. Each mobile ion species $i$ of the electrolyte is represented by their net charge $q_{i}$ and their bulk concentration $c_{i}^{0}$.

When calculating the fixed charge distribution $\rho^{f}$ of the nanopores, the individual $\mathrm{pKa}$ values of all titratable groups (ASP, GLU, TYR, HIS, ARG, LYS, and the $\mathrm{C}$ - and N-termini) were estimated with PROPKA ${ }^{71}$ (Supplementary Tables 2 , 3). A modified version of the PDB2PQR $\mathrm{P}^{72}$ software was then used to assign a radius and $\mathrm{pH}$-dependent partial charge to each atom in the model ("PQR" file format), taking into account the partial (de)protonated states of any residue whose $\mathrm{pKa}$ was close to the given $\mathrm{pH}$. First, the average protonated fraction $\left(f_{\mathrm{HA}}\right)$ of a residue at a given $\mathrm{pH}$ was calculated: $f_{\mathrm{HA}}=\left(1+10^{\mathrm{pH}-\mathrm{pKa}}\right)^{-1}$. Next, the partial charge of each atom in the residue $(\delta)$ was adjusted proportionally to the average protonation state: $\delta=\delta_{\mathrm{HA}} \times f_{\mathrm{HA}}+\delta_{\mathrm{A}^{-}} \times\left(1-f_{\mathrm{HA}}\right)$. Here $\delta_{\mathrm{HA}}$ and $\delta_{\mathrm{A}^{-}}$represent the partial charge of the atom in the protonated and the deprotonated states of the amino acid, respectively. Atomic charges and radii were based on the PARSE force field.

The homology models WtFraC and $\mathrm{ReFraC}$ were built from the FraC crystal structure (4TSY) ${ }^{50}$ using the VMD ${ }^{73}$ and MODELLER ${ }^{74}$ software packages.

The Adaptive Poisson-Boltzmann Solver (APBS) ${ }^{75}$ was then used to calculate the electrostatic potential maps for $\mathrm{WtFraC}$ and $\mathrm{ReFraC}$ at pH 4.5 and 7.5 in $1 \mathrm{M}$ $\mathrm{KCl}$. Briefly, each PQR file was processed by APBS and the "draw_membrane2" program (included with APBS) to set up and solve the full PBE in three sequential calculations with increasing precision (Supplementary Fig. 8). The nanopore molecular surface (1.4 ̊ probe) was used as the barrier between protein interior $(\epsilon$ $=10$, ion-inaccessible) and the electrolyte $(\epsilon=80)$. A lipid bilayer was included in the form of a $3 \mathrm{~nm}$-thick, dielectric slab ( $\epsilon=2$, ion-inaccessible) located at the center of FraC's transmembrane domain as determined in the OPM database ${ }^{76}$ The monovalent salt concentration was set to $1 \mathrm{M}$ and the radius of both ions was $2.0 \AA$ A. First, a coarse calculation was performed with a large box to mitigate boundary effects and to ensure proper conversion $\left(600 \times 600 \times 600 \AA^{3}\right.$ size, $1.86 \AA$ resolution, $\varphi_{\text {edge }}=0$ ). The coarse solution was then used in two sequential "focussing" calculations with a medium $\left(300 \times 300 \times 300 \AA^{3}\right.$ size, $0.93 \AA$ resolution, $\left.\varphi_{\text {edge }}=\varphi_{\text {coarse }}\right)$ and a fine box $\left(150 \times 150 \times 150 \AA^{3}\right.$ size, $0.47 \AA$ resolution, $\left.\varphi_{\text {edge }}=\varphi_{\text {medium }}\right)$. Further refinement of the grid did not result in a quantitatively different result. A sub-unit averaged electrostatic map was obtained by performing the same calculation eight times while rotating the atomic coordinates of the pore in steps of $45^{\circ}$ around the $z$-axis between each calculation and subsequently averaging the resulting electrostatic maps. Cross-sectional slices were plotted using PyMOL.

Electrical recording in planar lipid bilayers. Two compartments of the electrophysiology chamber were separated by a $25 \mu \mathrm{m}$ polytetrafluoroethylene film (Goodfellow Cambridge Limited) containing an aperture with a diameter of about $100 \mu \mathrm{m}$. To form a lipid bilayer, $\sim 5 \mu \mathrm{l}$ of hexadecane solution $(10 \% \mathrm{v} / \mathrm{v}$ hexadecane in pentane) was added to the polytetrafluoroethylene film. After $\sim 2 \mathrm{~min}, 0.5 \mathrm{ml}$ buffer was added to each compartment and $10 \mu \mathrm{l}$ of a $10 \mathrm{mg} / \mathrm{ml}$ solution of DPhPC, dissolved in pentane, directly added on top of the solutions. After brief waiting to allow for evaporation of pentane, silver/silver-chloride electrodes were submerged into each compartment. The ground electrode was connected to the cis compartment, the working electrode to trans side. A lipid bilayer spontaneously forms by lowering the buffer above and below the aperture in the polytetrafluoroethylene film. FraC oligomers were added to the cis side. Under an applied potential, the ionic current of $\mathrm{FraC}$ is asymmetric, allowing the determination of the orientation of FraC nanopores in the lipid bilayer. WtFraC nanopores showed the orientation as shown in Fig. 1, Supplementary Fig. 9, and Supplementary Table 4 when a higher conductance was measured at negative applied potential. Analytes were then added to cis compartment. Two kinds of buffer solutions were used for electrophysiology recording in this study depending on the $\mathrm{pH}$. At $\mathrm{pH} 7.5$, recordings were performed using $1 \mathrm{M} \mathrm{KCl}$ and $15 \mathrm{mM}$ Tris base. When the $\mathrm{pH}$ was varied from 7.5 to 4.5 , the buffer used contained $1 \mathrm{M} \mathrm{KCl}, 0.1 \mathrm{M}$ citric acid, and $180 \mathrm{mM}$ Tris base. FraC and ReFraC oligomers could insert into lipid bilayer from $\mathrm{pH} 4.5$ to 7.5

Data recording and analysis. Planar bilayer recordings were collected using a patch clamp amplifier (Axopatch 200B, Axon Instruments) and the data digitized with a Digidata $1440 \mathrm{~A} / \mathrm{D}$ converter (Axon Instruments). Data were acquired by using Clampex 10.4 software (Molecular Devices) and the subsequent analysis was carried out with Clampfit software (Molecular Devices). Events duration (dwell time), time between two events (inter-event time), blocked current levels $\left(I_{\mathrm{B}}\right)$, and open pore levels $\left(I_{\mathrm{O}}\right)$ were detected by "single channel search" function. $I_{\mathrm{res}} \%$, defined as $\left(I_{\mathrm{B}} / I_{\mathrm{O}}\right) \times 100$, was used to describe the extent of blockade caused by 
different biomarkers. Average inter-event times were calculated by binning the inter-event times and applying a single exponential fit to cumulative distributions.

Ion selectivity measurement. The ion permeability ratio $\left(\mathrm{K}^{+} / \mathrm{Cl}^{-}\right)$was calculated using the Goldman-Hodgkin-Katz equation (Eq. 1), which uses the reverse potential $\left(V_{\mathrm{r}}\right)$ as variable input. The activity of $\mathrm{KCl}$ at 1960 and $467 \mathrm{mM}$ was calculated using mean activity coefficients for 2000 and $500 \mathrm{mM} \mathrm{KCl}$, respectively ${ }^{77}$. The $V_{\mathrm{r}}$ was measured from extrapolation from I-V curves collected under asymmetric salt concentration condition. Individual FraC nanopores were reconstituted using the same buffer in both chambers (symmetric conditions, $840 \mathrm{mM}$ $\mathrm{KCl}, 15 \mathrm{mM}$ Tris base, $\mathrm{pH} 7.5,500 \mu \mathrm{l})$ to assess the orientation of the nanopore. About $400 \mu \mathrm{l}$ solution containing $3.36 \mathrm{M} \mathrm{KCl}, 15 \mathrm{mM}$ Tris base, $\mathrm{pH} 7.5$ was slowly added to cis chamber and $400 \mu \mathrm{l}$ of a buffered solution containing no $\mathrm{KCl}(15 \mathrm{mM}$ Tris base, $\mathrm{pH} 7.5$ ) was added to trans solution (trans:cis, $467 \mathrm{mM} \mathrm{KCl:} 1960 \mathrm{mM}$ $\mathrm{KCl}$ ). The solutions were mixed and I-V curves collected from -30 to $30 \mathrm{mV}$ with $1 \mathrm{mV}$ steps. Experiments at $\mathrm{pH} 4.5$ were carried out using the same method but using $0.1 \mathrm{M}$ citric acid buffered solutions. Initially, $500 \mu \mathrm{l} 840 \mathrm{mM} \mathrm{KCl}, 0.1 \mathrm{M}$ citric acid, $180 \mathrm{mM}$ Tris base buffer was added into both chambers and a single FraC channel obtained. Then, $400 \mu \mathrm{l}$ of $\mathrm{pH} 4.5$ solution containing $3.36 \mathrm{M} \mathrm{KCl}, 0.1 \mathrm{M}$ citric acid, $180 \mathrm{mM}$ Tris base was slowly added to cis chamber and $400 \mu \mathrm{l}$ of a buffered solution containing no KCl (0.1 M citric acid, $180 \mathrm{mM}$ Tris base, $\mathrm{pH} 4.5)$ was added to trans solution (thus yielding a trans:cis ratio of $467 \mathrm{mM} \mathrm{KCl}$ : $1960 \mathrm{mM} \mathrm{KCl}$ ). The solutions were mixed and I-V curves collected from -30 to $30 \mathrm{mV}$ with $1 \mathrm{mV}$ steps. The directionality of the ion selectivity was also tested by using high $\mathrm{KCl}$ concentration in trans chamber and low $\mathrm{KCl}$ concentration in the cis chamber (Supplementary Fig. 10; Supplementary Tables 5, 6). Ag/AgCl electrodes were surrounded with $2.5 \%$ agarose bridges containing $2.5 \mathrm{M} \mathrm{NaCl}$.

Data availability. The authors declare that the data supporting the findings of this study are available within the article and its Supplementary Information files or from the corresponding authors upon reasonable request.

Received: 4 April 2017 Accepted: 9 August 2017

Published online: 16 October 2017

\section{References}

1. Mathé, J., Aksimentiev, A., Nelson, D. R., Schulten, K. \& Meller, A. Orientation discrimination of single-stranded DNA inside the alpha-hemolysin membrane channel. Proc. Natl Acad. Sci. USA 102, 12377-12382 (2005).

2. Shim, J. W., Tan, Q. \& Gu, L. Q. Single-molecule detection of folding and unfolding of the G-quadruplex aptamer in a nanopore nanocavity. Nucleic Acids Res. 37, 972-982 (2009).

3. Kowalczyk, S. W., Tuijtel, M. W., Donkers, S. P. \& Dekker, C. Unraveling single-stranded DNA in a solid-state nanopore. Nano Lett. 10, 1414-1420 (2010).

4. Schneider, G. F. et al. DNA translocation through graphene nanopores. Nano Lett. 10, 3163-3167 (2010).

5. Liu, L., Yang, C., Zhao, K., Li, J. \& Wu, H. C. Ultrashort single-walled carbon nanotubes in a lipid bilayer as a new nanopore sensor. Nat. Commun. 4, 2989 (2013).

6. Johnson, R. P., Fleming, A. M., Beuth, L. R., Burrows, C. J. \& White, H. S. Base flipping within the alpha-hemolysin latch allows single-molecule identification of mismatches in DNA. J. Am. Chem. Soc. 138, 594-603 (2016).

7. Cao, C. et al. Discrimination of oligonucleotides of different lengths with a wild-type aerolysin nanopore. Nat. Nanotechnol. 11, 713-718 (2016)

8. Kasianowicz, J. J., Brandin, E., Branton, D. \& Deamer, D. W. Characterization of individual polynucleotide molecules using a membrane channel. Proc. Natl Acad. Sci. USA 93, 13770-13773 (1996).

9. Butler, T. Z., Pavlenok, M., Derrington, I. M., Niederweis, M. \& Gundlach, J. H. Single-molecule DNA detection with an engineered MspA protein nanopore. Proc. Natl Acad. Sci. USA 105, 20647-20652 (2008).

10. Stoddart, D., Heron, A. J., Mikhailova, E., Maglia, G. \& Bayley, H. Singlenucleotide discrimination in immobilized DNA oligonucleotides with a biological nanopore. Proc. Natl Acad. Sci. USA 106, 7702-7707 (2009).

11. Lieberman, K. R. et al. Processive replication of single DNA molecules in a nanopore catalyzed by phi29 DNA polymerase. J. Am. Chem. Soc. (2010).

12. McNally, B. et al. Optical recognition of converted DNA nucleotides for singlemolecule DNA sequencing using nanopore arrays. Nano Lett. 10, 2237-2244 (2010).

13. Franceschini, L., Mikhailova, E., Bayley, H. \& Maglia, G. Nucleobase recognition at alkaline $\mathrm{pH}$ and apparent $\mathrm{pKa}$ of single DNA bases immobilised within a biological nanopore. Chem. Commun. 48, 1520-1522 (2012).

14. Nivala, J., Marks, D. B. \& Akeson, M. Unfoldase-mediated protein translocation through an alpha-hemolysin nanopore. Nat. Biotechnol. 31, 247-250 (2013).
15. Movileanu, L., Schmittschmitt, J. P., Scholtz, J. M. \& Bayley, H. Interactions of peptides with a protein pore. Biophys. J. 89, 1030-1045 (2005).

16. Stefureac, R., Long, Y. T., Kraatz, H. B., Howard, P. \& Lee, J. S. Transport of alpha-helical peptides through alpha-hemolysin and aerolysin pores. Biochemistry 45, 9172-9179 (2006).

17. Goodrich, C. P. et al. Single-molecule electrophoresis of $\beta$-Hairpin peptides by electrical recordings and Langevin dynamics simulations. J. Phys. Chem. B 111, 3332-3335 (2007).

18. Wang, H. Y., Ying, Y. L., Li, Y., Kraatz, H. B. \& Long, Y. T. Nanopore analysis of beta-amyloid peptide aggregation transition induced by small molecules. Anal. Chem. 83, 1746-1752 (2011).

19. Mereuta, L. et al. Slowing down single-molecule trafficking through a protein nanopore reveals intermediates for peptide translocation. Sci. Rep. 4, 3885 (2014).

20. Gu, L. Q., Cheley, S. \& Bayley, H. Electroosmotic enhancement of the binding of a neutral molecule to a transmembrane pore. Proc. Natl Acad. Sci. USA 100, 15498-15503 (2003).

21. Firnkes, M., Pedone, D., Knezevic, J., Doblinger, M. \& Rant, U. Electrically facilitated translocations of proteins through silicon nitride nanopores: conjoint and competitive action of diffusion, electrophoresis, and electroosmosis. Nano Lett. 10, 2162-2167 (2010).

22. Yusko, E. C., An, R. \& Mayer, M. Electroosmotic flow can generate ion current rectification in nano- and micropores. ACS Nano 4, 477-487 (2010).

23. Soskine, M. et al. An engineered ClyA nanopore detects folded target proteins by selective external association and pore entry. Nano Lett. 12, 4895-4900 (2012).

24. Cressiot, B. et al. Protein transport through a narrow solid-state nanopore at high voltage: experiments and theory. ACS Nano 6, 6236-6243 (2012).

25. Nadanai, L. \& Ulrich, F. K. Electroosmotic flow rectification in conical nanopores. Nanotechnology 26, 275202 (2015).

26. Boukhet, M. et al. Probing driving forces in aerolysin and [small alpha]hemolysin biological nanopores: electrophoresis versus electroosmosis. Nanoscale 8, 18352-18359 (2016).

27. Asandei, A. et al. Electroosmotic Trap against the electrophoretic force near a protein nanopore reveals peptide dynamics during capture and translocation. ACS Appl. Mater. Interfaces 8, 13166-13179 (2016).

28. Fahie, M., Chisholm, C. \& Chen, M. Resolved single-molecule detection of individual species within a mixture of anti-biotin antibodies using an engineered monomeric nanopore. ACS Nano 9, 1089-1098 (2015).

29. Fahie, M. A., Yang, B., Mullis, M., Holden, M. A. \& Chen, M. Selective detection of protein homologues in serum using an OmpG nanopore. Anal. Chem. 87, 11143-11149 (2015).

30. Rotem, D., Jayasinghe, L., Salichou, M. \& Bayley, H. Protein detection by nanopores equipped with aptamers. J. Am. Chem. Soc. 134, 2781-2787 (2012)

31. Wang, S., Haque, F., Rychahou, P. G., Evers, B. M. \& Guo, P. Engineered nanopore of Phi29 DNA-packaging motor for real-time detection of single colon cancer specific antibody in serum. ACS Nano 7, 9814-9822 (2013).

32. Mohammad, M. M. et al. Engineering a rigid protein tunnel for biomolecular detection. J. Am. Chem. Soc. 134, 9521-9531 (2012).

33. Soskine, M., Biesemans, A., De Maeyer, M. \& Maglia, G. Tuning the size and properties of ClyA nanopores assisted by directed evolution. J. Am. Chem. Soc. 135, 13456-13463 (2013).

34. Van Meervelt, V., Soskine, M. \& Maglia, G. Detection of two isomeric binding configurations in a protein-aptamer complex with a biological nanopore. ACS Nano 8, 12826-12835 (2014).

35. Biesemans, A., Soskine, M. \& Maglia, G. A protein rotaxane controls the translocation of proteins across a ClyA nanopore. Nano Lett. 15, 6076-6081 (2015).

36. Soskine, M., Biesemans, A. \& Maglia, G. Single-molecule analyte recognition with ClyA nanopores equipped with internal protein adaptors. J. Am. Chem. Soc. 137, 5793-5797 (2015).

37. Plesa, C. et al. Fast translocation of proteins through solid state nanopores. Nano Lett. 13, 658-663 (2013).

38. Nir, I., Huttner, D. \& Meller, A. Direct sensing and discrimination among Ubiquitin and Ubiquitin chains using solid-state nanopores. Biophys. J. 108, 2340-2349 (2015).

39. Yusko, E. C. et al. Controlling protein translocation through nanopores with bio-inspired fluid walls. Nat. Nanotechnol. 6, 253-260 (2011).

40. Wei, R., Gatterdam, V., Wieneke, R., Tampe, R. \& Rant, U. Stochastic sensing of proteins with receptor-modified solid-state nanopores. Nat. Nanotechnol. 7 , 257-263 (2012).

41. Oukhaled, A. et al. Dynamics of completely unfolded and native proteins through solid-state nanopores as a function of electric driving force. ACS Nano 5, 3628-3638 (2011).

42. Balme, S. et al. Influence of adsorption on proteins and amyloid detection by silicon nitride nanopore. Langmuir 32, 8916-8925 (2016).

43. Yusko, E. C. et al. Real-time shape approximation and fingerprinting of single proteins using a nanopore. Nat. Nanotechnol. 12, 360-367 (2017). 
44. Li, W. et al. Single protein molecule detection by glass nanopores. ACS Nano 7, 4129-4134 (2013).

45. Steinbock, L. J. et al. Probing the size of proteins with glass nanopores. Nanoscale 6, 14380-14387 (2014).

46. Larkin, J., Henley, R. Y., Muthukumar, M., Rosenstein, J. K. \& Wanunu, M. High-bandwidth protein analysis using solid-state nanopores. Biophys. J. 106, 696-704 (2014)

47. Waduge, P. et al. Nanopore-based measurements of protein size, fluctuations, and conformational changes. ACS Nano 11, 5706-5716 (2017).

48. Wloka, C. et al. Label-free and real-time detection of protein ubiquitination with a biological nanopore. ACS Nano 11, 4387-4394 (2017).

49. Wloka, C., Mutter, N. L., Soskine, M. \& Maglia, G. Alpha-helical fragaceatoxin $\mathrm{C}$ nanopore engineered for double-stranded and single-stranded nucleic acid analysis. Angew. Chem. Int. Ed. Engl. 55, 12494-12498 (2016).

50. Tanaka, K., Caaveiro, J. M. M., Morante, K., González-Mañas, J. M. \& Tsumoto, K. Structural basis for self-assembly of a cytolytic pore lined by protein and lipid. Nat. Commun. 6, 6337 (2015).

51. Guo, W., Tian, Y. \& Jiang, L. Asymmetric ion transport through ion-channelmimetic solid-state nanopores. Acc. Chem. Res. 46, 2834-2846 (2013).

52. Piguet, F. et al. Electroosmosis through $\alpha$-hemolysin that depends on alkali cation type. J. Phys. Chem. Lett. 5, 4362-4367 (2014).

53. Wong, C. T. A. \& Muthukumar, M. Polymer capture by electro-osmotic flow of oppositely charged nanopores. J. Chem. Phys. 126, 164903 (2007).

54. Park, J. et al. Discovery and validation of biomarkers that distinguish mucinous and nonmucinous pancreatic cysts. Cancer Res. 75, 3227-3235 (2015).

55. Salama, M. et al. Endothelin-1 is a useful biomarker for early detection of bronchiolitis obliterans in lung transplant recipients. J. Thorac. Cardiovasc. Surg. 140, 1422-1427 (2010).

56. Wilson, A. M. et al. Beta2-microglobulin as a biomarker in peripheral arterial disease: proteomic profiling and clinical studies. Circulation 116, 1396-1403 (2007).

57. Ju, W. et al. Tissue transcriptome-driven identification of epidermal growth factor as a chronic kidney disease biomarker. Sci. Transl. Med. 7, 316ra193-316ra193 (2015).

58. Kobori, H. et al. Urinary angiotensinogen as a novel biomarker of the intrarenal renin-angiotensin system status in hypertensive patients. Hypertension 53, 344-350 (2009)

59. Stefureac, R. I., Trivedi, D., Marziali, A. \& Lee, J. S. Evidence that small proteins translocate through silicon nitride pores in a folded conformation. J. Phys. Condens. Matter 22, 454133 (2010).

60. Rincon-Restrepo, M., Mikhailova, E., Bayley, H. \& Maglia, G. Controlled translocation of individual DNA molecules through protein nanopores with engineered molecular brakes. Nano Lett. 11, 746-750 (2011).

61. Clarke, J. et al. Continuous base identification for single-molecule nanopore DNA sequencing. Nat. Nanotechnol. 4, 265-270 (2009).

62. Cracknell, J. A., Japrung, D. \& Bayley, H. Translocating Kilobase RNA through the staphylococcal alpha-hemolysin nanopore. Nano Lett. 13, 2500-2505 (2013).

63. Wanunu, M., Sutin, J., McNally, B., Chow, A. \& Meller, A. DNA translocation governed by interactions with solid-state nanopores. Biophys. J. 95, 4716-4725 (2008).

64. Talaga, D. S. \& Li, J. Single-molecule protein unfolding in solid state nanopores. J. Am. Chem. Soc. 131, 9287-9297 (2009).

65. Freedman, K. J. et al. Chemical, thermal, and electric field induced unfolding of single protein molecules studied using nanopores. Anal. Chem. 83, 5137-5144 (2011).

66. Freedman, K. J., Haq, S. R., Edel, J. B., Jemth, P. \& Kim, M. J. Single molecule unfolding and stretching of protein domains inside a solid-state nanopore by electric field. Sci. Rep. 3, 1638 (2013).

67. Rowghanian, P. \& Grosberg, A. Y. Electrophoretic capture of a DNA chain into a nanopore. Phys. Rev. E Stat. Nonlin. Soft Matter Phys. 87, 042722 (2013).

68. Franceschini, L., Brouns, T., Willems, K., Carlon, E. \& Maglia, G. DNA translocation through nanopores at physiological ionic strengths requires precise nanoscale engineering. ACS Nano 10, 8394-8402 (2016).

69. Yao, Y., Margreet, D., Jetty van, G., Dick de, R. \& Chirlmin, J. Single-molecule protein sequencing through fingerprinting: computational assessment. Phys. Biol. 12, 055003 (2015).
70. Miles, G., Cheley, S., Braha, O. \& Bayley, H. The staphylococcal leukocidin bicomponent toxin forms large ionic channels. Biochemistry 40, 8514-8522 (2001).

71. Li, H., Robertson, A. D. \& Jensen, J. H. Very fast empirical prediction and rationalization of protein pKa values. Proteins 61, 704-721 (2005).

72. Dolinsky, T. J., Nielsen, J. E., McCammon, J. A. \& Baker, N. A. PDB2PQR: an automated pipeline for the setup of Poisson-Boltzmann electrostatics calculations. Nucleic Acids Res. 32, W665-W667 (2004).

73. Humphrey, W., Dalke, A. \& Schulten, K. VMD: visual molecular dynamics. J. Mol. Graph. 14, 33-38 (1996).

74. Sali, A. \& Blundell, T. L. Comparative protein modelling by satisfaction of spatial restraints. J. Mol. Biol. 234, 779-815 (1993).

75. Baker, N. A., Sept, D., Joseph, S., Holst, M. J. \& McCammon, J. A. Electrostatics of nanosystems: application to microtubules and the ribosome. Proc. Natl Acad. Sci. USA 98, 10037-10041 (2001).

76. Lomize, M. A., Lomize, A. L., Pogozheva, I. D. \& Mosberg, H. I. OPM: orientations of proteins in membranes database. Bioinformatics 22, 623-625 (2006).

77. Lide, D. R. CRC Handbook of Chemistry and Physics 84th edn (Taylor \& Francis, 2003).

78. Søndergaard, C. R., Olsson, M. H. M., Rostkowski, M. \& Jensen, J. H. Improved treatment of ligands and coupling effects in empirical calculation and rationalization of pKa Values. J. Chem. Theory Comput. 7, 2284-2295 (2011).

79. Olsson, M. H., Sondergaard, C. R., Rostkowski, M. \& Jensen, J. H. PROPKA3: consistent treatment of internal and surface residues in empirical $\mathrm{pKa}$ predictions. J. Chem. Theory Comput. 7, 525-537 (2011)

\section{Acknowledgements}

We thank Carlos de Lannoy for helping to write a custom R script for creating heatplots and histograms. This work is financially supported by ERC starting grant, SMEN 260884

\section{Author contributions}

G.H., M.S., C.W., G.M. designed the experiments. C.W., G.M. supervised the project. G.H. performed the experiments and data analysis. K.W. conducted the simulation work G.H., K.W., C.W., G.M. wrote the manuscript and M.S. contributed to the writing.

\section{Additional information}

Supplementary Information accompanies this paper at 10.1038/s41467-017-01006-4

Competing interests: The work by C.W. was sponsored by Oxford Nanopore Technologies Ltd. The remaining authors declare no competing financial interests.

Reprints and permission information is available online at http://npg.nature.com/ reprintsandpermissions/

Publisher's note: Springer Nature remains neutral with regard to jurisdictional claims in published maps and institutional affiliations.

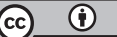

Open Access This article is licensed under a Creative Commons Attribution 4.0 International License, which permits use, sharing, adaptation, distribution and reproduction in any medium or format, as long as you give appropriate credit to the original author(s) and the source, provide a link to the Creative Commons license, and indicate if changes were made. The images or other third party material in this article are included in the article's Creative Commons license, unless indicated otherwise in a credit line to the material. If material is not included in the article's Creative Commons license and your intended use is not permitted by statutory regulation or exceeds the permitted use, you will need to obtain permission directly from the copyright holder. To view a copy of this license, visit http://creativecommons.org/ licenses/by/4.0/

(C) The Author(s) 2017 